\title{
Konvergensi media pada perkembangan radio komersial di Yogyakarta (studi kasus pada radio Geronimo FM dan radio Swaragama $\mathrm{FM}$ )
}

\author{
Fitriana Nur Annisa a,1,* \\ ${ }^{\mathrm{a}}$ Universitas Muhammadiyah Yogyakarta \\ ${ }^{1}$ fitrianur@gmail.com*; \\ * corresponding author
}

Article history

Received 06-01-2021

Revised 18-01-2021

Accepted 02-02-2021

Keywords

Konvergensi Media

Radio

Internet

Media Sosial

Media Tradisional

\begin{abstract}
Perkembangan teknologi memungkinkan media konvensional khususnya media penyiaran televisi dan radio yang bersifat satu waktu dapat berubah bersifat multi-channel yang juga merupakan bagian dari sifat konvergensi media. Konvergensi media merupakan salah satu perkembangan media massa yang banyak melibatkan faktor teknologi dalam prosesnya. Kehadiran internet membuat media konvensional menerapkan konsep konvergensi media yang memunculkan tren seperti munculnya e-paper, e-book, radio streaming, dan media sosial. Dalam penelitian ini, penulis memfokuskan pada bagaimana radio sebagai media tradisional dapat terus berkembang dengan menerapkan konvergensi media. Garis besar tulisan ini membahas radio yang mulai berkolaborasi dengan media baru dan pengaruhnya terhadap perkembangan Radio Geronimo FM dan Radio Swaragama FM di Yogyakarta. Penelitian ini menggunakan metode studi kasus dengan teknik pengumpulan data berupa wawancara mendalam, observasi, dan dokumentasi dengan pihak internal Radio Geronimo FM dan Radio Swaragama FM. Hasil dari penelitian ini adalah kedua radio sudah sangat memaksimalkan konvergensi media dengan baik yang dibuktikan dengan perluasan jangkauan pendengar, memperbesar kesempatan pengiklan dengan media sosial, dan perluasan ekonomi mengacu konglomerasi ekonomi.
\end{abstract}

This is an open access article under the CC-BY-SA license.

\section{Introduction}

Media sosial merupakan suatu jaringan infomasi terbaru yang digabungkan dengan teknologi informasi yang menggunakan suatu bentuk komunikasi berupa konten interaktif dan userproduction, serta hubungan interpesonal yang diciptakan dan dipelihara. Media sosial dapat dilihat dari bagaimana hubungan individu dengan perangkat media Nursam (2017) yang kemudian media sosial ini fokus terhadap eksistensi pengguna atau individu dengan menyediakan fasilitas dalam beraktivitas maupun berkolaborasi dalam lingkup online. Karena itulah, media sosial juga disebut sebagai medium online yang menguatkan hubungan antarpengguna juga membentuk ikatan sosial (Meersohn, 2005).

Perkembangan teknologi memungkinkan media konvensional khususnya media penyiaran televisi dan radio yang bersifat satu waktu dapat berubah bersifat multi- channel yang juga merupakan bagian dari sifat konvergensi media. Konvergensi media merupakan salah satu perkembangan media massa yang banyak melibatkan faktor teknologi dalam prosesnya. Kehadiran internet membuat media konvensional menerapkan konsep konvergensi media yang memunculkan tren seperti munculnya e- paper, e-book, radio streaming, dan media sosial. Konvergensi adalah 
terkombinasinya berbagai jenis media yang sebelumnya dianggap berbeda seperti surat kabar, komputer, radio, televisi, media-media ini disatukan ke dalam sebuah media tunggal (C. Sprapti Dwi Takariani, 2009). Penyatuan akan beberapa media disebut dengan kolaborasi antarmedia (Hamna, 2017).

Tren penerapan konvergensi media sendiri telah banyak dilakukan oleh beberapa industri media penyiaran guna menunjang kualitas dan memperluas wilayah audience. Seperti yang terjadi di Eropa, yaitu Norwegia. Pemerintah Norwegia membuat keputusan untuk mengalihkan siaran radio FM ke perangkat radio Digital Audio Broadcasting (DAB) dengan tujuan memberikan penawaran berbagai pilihan penyiaran yang lebih luas dengan kualitas suara yang lebih baik. Norwegia menjadi negara yang pertama kali meluncurkan penyiaran radio berbasis digital melalui Norwegia Broadcastng Corporation (NRK) pada 1 Juni 1995, kemudian disusul oleh BBC dan Radio Swedia pada September 1995. Persiapan transisi dari siaran FM ke digital, dimulai sejak saat itu (Jandevi, 2019a).

Selanjutnya, di Portugal, Radio RFM dan radio komersil memiliki situs website dengan sumber daya multimedia yang terbilang lengkap seperti layanan streaming yang berisikan siaran langsung, teks dan berita, bahkan video yang dibuat sesuai permintaan berisikan humor maupun musik yang dibuat secara khusus. Selain itu, mereka juga aktif menggunakan jejaring sosial yang memungkinkan penyiar untuk dapat berinteraksi langsung dengan pendengar (Cordeiro, 2013).

Adanya penerapan tren konvergensi media ini mengakibatkan banyaknya media konvensional khususnya media cetak lokal di Indonesia gulung tikar pada tahun 2015 dan beralih ke digital, membuat masa depan radio juga dipertanyakan. Karena media cetak dan media penyiaran radio merupakan media tradisional. Data Nielsen menyebutkan bahwa jumlah pendengar radio konvensional di Indonesia menurun tiap tahunnya. Kasus menurunnya pendengar menyebabkan beberapa radio gulung tikar. Radio Voice of Amerika (VOA) yang berada di Indonesia tutup pada tahun 2016 karena adanya pemangkasan anggaran dari Broadcasting Broad of Governor atau BBG yang menaungi VOA Indonesia sehingga berdampak pada siaran Radio VOA (Jaya, 2019).

Masih berada di hati masyarakat Indonesia, walapun persentasi pendengar menurun, radio tetap berkumandang dan menjadi media untuk mendapatkan informasi maupun hiburan karena radio mudah dijangkau dengan biaya yang sedikit (Baade, 2015). Sepanjang tahun 2016-2018 Nielsen Radio Audience Measurement merangkum bahwa dalam rentang tahun tersebut penetrasi radio turun perlahan dari $37 \%$ menjadi $34,3 \%$ pada tahun 2018. Namun, data hasil survey Nielsen pada tahun 2019 menunjukkan adanya kenaikan menjadi 36,3\%. Hal ini bagaikan angin segar bagi media penyiaran radio karena dapat bersinergi dengan terus melakukan perubahan di tengah arus digitalisasi.

Pengguna media sosial yang semakin bertambah per-harinya juga menjadi peluang yang besar untuk radio dapat menjangkau target audience dengan lebih luas. Data dari Hootsuite pada tahun 2019 menunjukan bahwa sebanyak 150 juta jiwa penduduk Indonesia aktif mengakses media sosial dengan menembus angka $56 \%$ dari total jumlah populasi penduduk. Sedangkan jumlah pengakses media sosial melalui telepon genggam sebanyak 130 juta jiwa dengan persentase $48 \%$ (Ulfah \& Barry, 2019).

Sementara penelitian ini akan fokus pada bagaimana dua radio komersial di Yogyakarta yaitu Radio Geronimo FM dan Radio Swaragama FM dalam melakukan adaptasi dan penerapan konvergensi melalui berbagai kanal media sosial di era konvergensi media pada saat ini untuk mempertahankan dan meningkatkan jumlah pendengar serta mengembangkan sayap ekonomi dengan memanfaatkan konvergensi media khususnya dalam segi dimensi teknologi dan dimensi ekonomi (Jandevi, 2019b).

Berdasarkan penelitian terdahulu, Radio Geronimo FM dan Radio Swaragama FM menarik dan layak untuk diteliti sebagai objek konvergensi media. Hal ini dikarenakan penelitian mengenai konvergensi media penyiaran belum banyak dilakukan. Terlebih kedua radio lokal tersebut termasuk radio komersial dengan segmentasi anak muda yang dikenal di Yogyakarta dan keduanya memiliki rentang usia yang cukup jauh yaitu pada tahun 2020 ini Radio Geronimo FM berusia 49 tahun sementara Radio Swaragama FM berusia 21 tahun. 
Penelitan ini penting dilakukan mengingat kehadiran internet pada era digitalisasi ini menjadi kompetitor utama media konvensional khususnya radio. Dalam hal ini, apabila radio tidak memiliki rancangan khusus dalam menerapkan konvergensi media, maka dapat dikatakan masa depan industri penyiaran radio tidak akan bertahan lama yang kemudian posisi radio akan digantikan media dengan berbagai kanal media baru yang lebih menarik.

\section{Theorotocal Framework}

Penelitian berjudul Konvergensi Media dalam Perkembangan Radio Komersial di Yogyakarta menggunakan jenis penelitian analisis deskriptif kualitatif. Di mana sifat deskriptif mengarah untuk menggambarkan bagaimana upaya yang dilakukan oleh Radio Geronimo FM dan Radio Swaragama FM dalam mengadopsi dan beradaptasi dengan konvergensi media. Whitney dalam (Pujileksono, 2009) mengatakan bahwa penelitian analisis deskriptif merujuk pada pencarian fakta dengan intrepretasi yang akurat. Penelitian ini mempelajari suatu kasus dalam masyarakat, pencarian data dengan situasi tertentu. Singkatnya, penelitian deskriptif mendeskripsikan keadaan dan tahapantahapan perkembangannya (Rahmat, 2009).

Penelitian ini menggunakan metode studi kasus. Studi kasus merupakan salah satu metode penelitian ilmu sosial yang dilakukan untuk mengkaji sebuah fenomena unik individu, organisasi dan politik yang relevan dengan fenomena kontemporer atau masa kini (Winarno, 2012). Esensi utama dari studi kasus yang dijelaskan oleh Schramm (1994) dalam mengemukakan bahwa jenis studi kasus menjelaskan mengenai keputusan- keputusan yang dipilih, bagaimana implementasinya dan apa hasilnya.

Studi kasus sebagai sebuah penelitian memiliki hakikat yang menggali suatu fenomena secara mendalam dengan menggunakan pengumpulan data selama masalah atau kasus terjadi. Studi kasus dilakukan dalam latar belakang yang alamiah, artinya proses pengambilan infomasi dilakukan di kehidupan nyata dan tidak ada campur tangan dari pihak luar.

Studi kasus mempelajari dan menerangkan konvergensi media di Radio Geronimo FM dan Radio Swaragama FM secara natural. Pada intinya, studi kasus berusaha untuk mengungkap mengapa suatu keputusan diambil dan bagaimana keputusan diambil (Rahardjo, 2017). Dalam studi kasus, ada beberapa konsep dimana fenomena disatukan dengan kejadian-kejadian yang ada didalamnya, adapun konsep tersebut yaitu (a) time and place King (1991) ; (b) time and activity dan (c) definition and context.

Studi kasus sebagai sebuah penelitian memiliki karakteristik sebagai berikut (Winarno, 2012):

1) Menempatkan objek penelitian sebagai sebuah kasus

Penerapan konvergensi media di Radio Geronimo FM dan Radio Swaragama FM dilihat sebagai sebuah kasus dan merupakan sistem kesatuan menyeluruh. Kasus bersifat menyeluruh, artinya konvergensi media di Radio Geronimo FM dan Radio Swaragama FM tidak dapat disamakan sebagai contoh atau sample yang mewakili.

2) Memandang kasus sebagai fenomena yang bersifat kontemporer

Bersifat kontemporer berarti, penerapan konvergensi media di Radio Geronimo FM dan Swaragama FM merupakan kasus yang sedang terjadi atau telah selesai (masa kini) yang kemudian dampak implementasi dan tantangannya masih dapat dirasakan hingga saat ini.

3) Dilakukan pada kondisi kehidupan sebenarnya

Studi kasus meneliti sebuah kasus di kehidupan nyata, yang berarti dilakukan berdasarkan kondisi nyata yang sebenarnya terjadi dalam penerapan konvergensi media di Radio Geronimo FM dan Radio Swaragama FM. 
4) Menggunakan berbagai sumber data

Penelitian ini bersumber dari proses pengambilan data dari pihak internal Radio Geronimo FM dan Radio Swaragama FM yang diharapkan dapat memperoleh hasil yang akurat dan luas mengenai konvergensi media (Fadillah, 2019).

5) Menggunakan teori sebagai acuan

Berdasarkan teori para ahli yang telah dikemukakan dalam penelitian konvergensi media di Radio Geronimo FM dan Radio Swaragama FM dapat mengembangkan teori terkait hasil penelitian.

Oleh karena itu, penelitian berjudul Konvergensi Media dalam Radio Komersial di Yogyakarta (Studi Kasus pada Radio Geronimo FM dan Radio Swaragama FM) menggunakan studi kasus untuk mendalami hasil temuan dengan mempelajari, memahami, dan menerangkan mengenai pengadopsian konvergensi media di Radio Geronimo FM dan Radio Swaragama FM .

\section{Method}

Teknik pengumpulan data merupakan langkah yang penting dalam penelitian kualitatif, karena tujuan dari penelitian adalah mendapatkan data. Teknik pengumpulan data ini harus disesuaikan dengan jenis penelitian dan data apa yang dibutuhkan. Adapun teknik pengumpulan data pada penelitian ini adalah sebagai berikut.

1) Wawancara Mendalam (In-depth Interview)

Wawancara mendalam dilakukan untuk mencari tahu lebih mendalam tentang topik atau isu tertentu. Dalam kata lain, wawancara secara mendalam lebih fokus walaupun sebenarnya percakapan yang dilakukan lebih luas. Menurut Moleong (2006) wawancara mendalam merupakan salah satu cara untuk menemukan jawaban yang lebih dalam walau waktu yang dibutuhkan lebih lama dibanding dengan wawancara biasa (Gunawan, 2016). Wawancara dilihat sebagai bentuk proses interaksi komunikasi yang dilakukan oleh dua orang atau lebih, yang mengedepankan kepercayaan atau trust sebagai landasan dalam proses memahami (Herdiansyah, 2010).

2) Observasi

Definisi observasi dalam riset kualitatif yaitu proses melihat lebih dalam subjek penelitian dengan lingkungannya dan melakukan proses perekaman atau pemotretan tanpa merubah kondisi alamiah subyek dengan lingkungan sosialnya (Herdiansyah, 2010), Pada dasarnya observasi tidak hanya mencatat perilaku subyek penelitian namun juga kepada sistem yang sedang diterapkan dan peneliti harus mampu memprediksi apa yang mendasari sistem tersebut dibuat.

\section{3) Dokumentasi}

Dokumentasi adalah suatu cara pengumpulan data dengan cara mengumpulkan dokumen dari informan atau sumber untuk lebih mengetahui subyek penelitian. Menurut (Sugiyono, 2016) dokumentasi menjadi pelengkap dari penggunaan teknik wawancara dan observasi yang kemudian hasil dari penelitian akan lebih kredibel. Dokumentasi dapat berbentuk buku, arsip maupun dokumen, angka maupun gambar yang relevan dengan penelitian. Melalui teknik ini, penelitian konvergensi media dalam radio komersial di Yogyakarta ini mengumpulkan dokumen, literatur, dan buku yang relevan. Peneliti juga melakukan penelusuran via online seperti website guna menambah infomasi dan data tambahan.

\section{Results and Discussion}

Pengambilan informan dilakukan melalui teknik purposive sampling untuk memilih empat informan yang membantu untuk memenuhi tujuan penelitian yaitu untuk mengetahui, mendeskripsikan, dan menarik kesimpulan mengenai penerapan konvergensi media di Radio Geronimo FM dan Radio Swaragama FM. Kedua informan tersebut diambil dari pihak internal Radio Geronimo FM dan Radio Swaragama FM yang masing-masing berasal dari divisi yang berbeda dan memiliki kemampuan untuk menjawab pertanyaan mengenai konvergensi media yang diterapkan oleh Radio Geronimo FM dan radio Swaragama FM. Berikut penulis sajikan data untuk memberikan profil masing-masing informan. 
Informan pertama yang diwawancarai adalah Rino Gatot Sulistyanto, di Radio Geronimo FM beliau menjabat sebagai General Manager dan sudah bekerja di radio tersebut selama 25 tahun. Wawancara dilakukan secara daring karena kebijakan perusahaan untuk membatasi tamu untuk berkunjung karena pandemi Covid-19. Wawancara dilakukan pada 22 Juni 2020. Sebagai seorang General Manager atau biasa disebut 'kepala rumah tangga perusahaan' Rino Gatot Sulistyanto sangat mampu menjawab pertanyaan-pertanyaan mengenai konvergensi media di Radio Geronimo FM.

Informan kedua yang peneliti wawancarai adalah Mutya Annisa. Ia telah bekerja di Radio Geronimo FM selama 5 tahun sebagai penyiar dan merangkap sebagai Chief Digital Content. Mutya Annisa di wawancarai pada tanggal 2 Agustus 2020 melalui daring. Dengan pengalaman bekerja dalam bidang konten media, Mutya memiliki pengetahuan yang dalam mengenai ide konten yang menarik. Mutya sebagai penyiar cukup memiliki andil besar khususnya dalam media sosial Radio Geronimo FM.

Informan ketiga yang diwawancarai adalah Bonny Prasetya. Menjabat sebagai Head of Program Director and Music Director di Swaragama FM dan anak radio dari Swaragama FM yaitu Jogja Family FM, Studio IZ Radio (Bandung), Swaragama FM (Serang, Banten). Beliau sudah bekerja untuk Radio Swaragama FM selama 14 tahun. Saat diwawancarai pada 25 Juni 2020, beliau menjawab pertanyaan-pertanyaan seputar konvergensi media yang diterapkan oleh Radio Swaragama FM dengan sangat lengkap dan jelas.

Informan terakhir yang di wawancarai adalah Boma Ardhian. Bekerja untuk Radio Swaragama FM sejak tahun 2001. Memiliki jam terbang tinggi dalam dunia industri kreatif penyiaran, Boma Ardhian awalnya menjabat sebagai creative mixman lalu merambah ke executive producer, kemudian broadcast manager, lalu pada tahun 2014 menjabat sebagai digital media manager. Pada tahun 2014 hingga 2016, Boma ditugaskan menjadi broadcast manager di Radio Jogja Family FM yang dibawahi oleh Swaragama Network. Saat ini, Boma Ardhian fokus menjabat sebagai Chief Executive Officer (CEO) di IMPRESI (Digital Agenct \& Production House) milik Swaragama Network yang juga turut andil dalam pembuatan konten di Radio Swaragama FM.

1) Konvergensi Media di Radio Geronimo FM dan Radio Swaragama FM

Wawancara terkait pembahasan konvergensi media di Radio Geronimo FM dan Radio Swaragama FM dilakukan oleh dua informan yaitu Rino Gatot Sulistyanto selaku General Manager Radio Geronimo FM dan Bonny Prasetya selaku Head of Program Director and Music Director Radio Swaragama FM. Pembahasan konvergensi media di kedua radio difokuskan oleh dua informan tersebut yang memang terlibat langsung dan memiliki kemampuan di bidangnya. Guna beradaptasi dengan kemajuan teknologi yang begitu pesat saat ini, radio berusaha untuk tetap ada dengan menerapkan konsep konvergensi media. Dimana media konvensional berkolaborasi dengan media baru. Radio Geronimo dan Radio Swaragama merupakan radio konvensional besar di Kota Yogyakarta. Radio Geronimo berdiri pada tahun 1971 dan mulai menerapkan konvergensi media pada tahun 2014 dan terus melakukan penyempurnaan sampai saat ini. Sementara itu, Radio Swaragama tergolong radio muda yang lahir pada tahun 2000 dan mulai menerapkan konvergensi media pada tahun yang sama. Pada saat itu, Radio Swaragama satu-satunya radio yang memiliki website yang masih berisikan informasi mengenai adanya sebuah radio bernama Swaragama dan layanan streaming.

\section{2) Produk Media dan Tata Kelola Media}

Guna menjawab tantangan dan perkembangan zaman serta memenuhi kebutuhan pasar dalam mengakses informasi, Radio Geronimo FM dan Radio Swaragama FM mengembangkan berbagai platform seperti platform media streaming dan media sosial. Informasi yang kemudian didistribusikan oleh platform dan kanal media lain tentunya melewati porses manajemen dan prinsip pengolahan konten. Proses manajemen produk media atau konten ini mengikuti prinsip mengumpulkan ide konten mendistribusikan konten, dan evaluasi. Media sosial Radio Geronimo FM dan Radio Swaragama FM ini dijalankan oleh masing-masing divisi di kedua radio.

Selain web streaming, Radio Geronimo FM dan Radio Swaragama FM memililiki media sosial. Media sosial Radio Geronimo FM dijalankan oleh Mutya Annisa sementara Radio Swaragama FM 
dijalankan oleh Bastian. Berikut adalah rincian akun media sosial yang digunakan oleh Radio Geronimo FM dan Radio Swaragama FM:

a) Facebook

Akun Facebook Radio Geronimo FM dibuat pada tahun 6 Agustus 2010, dengan jumlah pengikut sebanyak 19.939, dan penyuka halaman sebanyak 20.022 orang. Konten yang disajikan pada akun Facebook ini antara lain siaran langsung ketika on-air siaran. Selain itu, artikel yang berkaitan dengan ajakan dan himbauan mengenai kesehatan. Dapat disimpulkan, Radio Geronimo FM tidak terlalu aktif mengunggah konten di Facebook dilihat dari waktu postingan yang jarang meng-update postingan.

\section{b) Twitter}

Radio Geronimo FM memiliki akun Twitter @geronimofm. Penggunaan akun Twitter oleh Radio Geronimo FM terbilang aktif dalam kegiatan on-air maupun off-air dalam menyapa pendengarnya. Jumlah pengikut akun Twitter Radio Geronimo FM menurut data berjumlah 102.000 pengikut dengan 305.900 tweet. Akun Twitter @ geronimofm lahir pada bulan Desember 2009.

\section{c) Instagram}

Radio Geronimo memiliki akun Instagram @geronimofm. Ketika melakukan penelitian, tercatat sebanyak 10.300 pengikut dengan 3.214 postingan. Konten yang dimat di akun Instagram @ geronimofm memiliki karakteristik sendiri, warna yang memang diselaraskan dengan logo Radio Geronimo FM. Akun Instagram memuat mengenai artikel berita, poster program, kegiatan siaran, dan video.

\section{d) Channel YouTube}

Radio Geronimo FM dan Radio Swaragama FM juga memanfaatkan YouTube sebagai wadah untuk memperluas pendengar. Akun atau channel YouTube Radio Geronimo dapat dijumpai dengan nama Geronimo FM yang memiliki 393 subscribers dengan 27 video.

\section{e) Aplikasi Mobile}

Radio Geronimo FM dan Radio Swaragama FM menyediakan aplikasi mobile agar tetap terhubung dan memudahakan pendengar untuk mendengarkan radio kesayangan, aplikasi tersebut dapat diunduh melalui Play Store untuk pengguna android dan Apps Store untuk pengguna iOS. Radio Geronimo FM merilis aplikasi ini pada 16 Agustus 2017 dan memperbaharuinya pada tahun 2018.

\section{3) Konvergensi Media Radio Geronimo dan Radio Swaragama FM}

Tren konvergensi media mulai sering diperbincangkan sejak kemunculan internet yang membawa perubahan dalam hal teknologi komunikasi. Radio Geronimo FM mulai menjawab perkembangan teknologi melalui konvergensi media pada tahun 2014, sementara Radio Swaragama FM dari awal pembentukan pada tahun 1999 stasiun radio sudah mulai mengikuti tren teknologi dengan memiliki website. Pada saat itu, Radio Swaragama FM adalah satu-satunya radio di Yogyakarta yang memiliki website, walaupun konsumsi internet belum seperti sekarang. Kedua radio ini memiliki segementasi pendengar anak muda yang berusia 18-35 tahun, dimana anak muda sangat dekat dengan perubahan arus teknologi sehingga kedua radio menyelaraskan arus dengan memiliki berbagai platform seperti media online dan berbagai kanal media sosial. Pengadopsian konvergensi media dengan memiliki multiplatform membuat struktur media penyiaran, telekomunikasi, penerbitan, dan industri teknologi menjadi lebih fleksibel menurut Flaw dalam (Dwyer, 2010).

\section{4) Produk Media dan Tata Kelola Media}

Menjawab perkembangan zaman dan memenuhi kebutuhan informasi bagi konsumen, Radio Geronimo FM dan Radio Swaragama FM mengembangkan berbagai platform seperti Geronimo.fm, aplikasi mobile Geronimo FM,

Swaragamafm.com, serta melalui kanal digital lainnya yaitu, media sosial. Informasi dan berita yang didistribusikan oleh platform dan kanal media yang berbeda ini tentunya melewati proses manajemen dan pengolahan konten. Agar tetap terstruktur dan menarik prouk media ini melewati prinsip pengumpulan bahan konten, editing, distribusi konten, dan evaluasi konten. 
Peneliti telah menganalisis dan mendapatkan hasil bagaimana konvergensi media yang dilakukan oleh Radio Geronimo FM dan Radio Swaragama FM dalam berkolaborasi dengan media baru. Berdasarkan hasil wawancara dan temuan penelitian, kedua radio ini menggunakan jenis media baru sebagai pendukung system operational penyiaran dan juga sebagai perangkat untuk menjalin interaksi dengan pendengar. Media utama yang digunakan oleh Radio Geronimo FM dan Radio Swaragama FM adalah media online web streaming dan berbagai kanal media sosial.

Memasuki era konvergensi media ini, Tindakan yang diambil oleh Radio Geronimo FM dan Radio Swaragama FM terkait kolaborasinya dengan media baru merupakan tindakan cerdas dan sangat baik yang juga mampu memprediksi kebutuhan konsumen dan berusaha untuk tetap 'hidup' dengan berinovasi dan berkreasi. Meminjam istilah dari Henry Jenkis, bahwa media lama tidak akan pernah mati. Masih ada segmentasi khusus dimana masyarakat masih membutuhkan media konvensional.

Pada akhir bahasan, penulis menyimpulkan bahwa hasil analisis ini membuktikan bahwa konvergensi media telah mengaburkan banyak hal dari definisi akan media, pola masyrakat, dan berubahnya sudut pandang dan cara pandang masyarakat dalam menggunakan media. Namun, berkat adanya era konvergensi media, radio menjadi semakin berkembang ke arah yang lebih baik. Walaupun pengadopsian konvergensi media belum sepenuhnya dilakukan, hal ini tentu akan memicu sebuah ide untuk terus melakukan perbaikan di kemudian hari.

\section{Conclusion}

Berdasarkan hasil pembahasan pada bab sebelumnya, dapat disimpulkan bahwa Radio Geronimo FM dan Radio Swaragama FM memanfaatkan konvergensi media dalam melaksanakan kegiatan onair dan mendistribusikan informasi berupa konten melalui media digital seperti web streaming, berbagai kanal media sosial, dan aplikasi mobile. Kehadiran media baru ini sebagai bagian dari media konvensional yang hadir guna memperkuat fungsi media konvensional penyiaran radio untuk memperluas jangkauan pendengar melalui distribusi penyiaran dan informasi yang lebih beragam.

Radio Geronimo FM dan Radio Swaragama FM melihat bahwa media online merupakan media yang efektif untuk mendistribusikan konten, meningkatkan jumlah pendengar, dan membesarkan peluang pengiklan untuk memasang iklan di radio. Hal ini dikarenakan bahwa konvergensi mengintegrasikan tiga fitur unik yaitu, kemampuan multimedia berdasarkan platform digital, kualitas interaktif media online, dan tatanan fitur-fitur media massa konvensional untuk mengatasi penurunan jumlah pendengar terhadap radio. Menambah platform media web streaming dan penciptaan aplikasi mobile, sedikit banyak mampu menaikkan jumlah pendengar pada media konvensional khususnya radio karena pendengar tidak harus memiliki radio kompo.

Peneliti beranggapan meski Radio Geronimo FM dan Radio Swaragama FM melakukan konvergensi media dengan menggunakan beberapa bentuk media baru dalam kegiatan menyebarkan konten dan kegiatan siaran radio, pelaksanaan penerapan sudah terbilang cukup efektif. Hanya saja, Radio Geronimo FM dan Radio Swaragama FM terlalu sering menggunakan bentuk media sosial Instagram. Hal ini membuat media sosial lain terkesampingkan juga menyebabkan jalan konvergensi tidak berjalan lancer sesuai tujuan yang diinginkan.

Kesimpulan dari peneliti, dalam mengadopsi konvergensi media secara luas Radio Geronimo FM masih mengikuti arus tren new media dan sudah sangat memaksimalkannya dalam penggunaan dan pengelolaannya. Sementara untuk Radio Swaragama FM penerapan konvergensi selain mengikuti new media, radio ini sudah sangat baik dalam mengadopsi konvergensi karena sudah melahirkan unit bisnis lain. 


\section{References}

Baade, C. (2015). Radio. In The Routledge Reader on the Sociology of Music. https://doi.org/10.4324/9780203736319-34

C. Sprapti Dwi Takariani, S. (2009). Jurnal penelitian komunikasi. Ilmu Komunikasi.

Cordeiro, G. Í. (2013). Etnografía. Arxiu d'Etnografia de Catalunya. https://doi.org/10.17345/aec13.300-304

Fadillah, D. (2019). DINAMIKA KOMUNIKASI ORGANISASI MUHAMMADIYAH DIY DAN PENCALONAN SENATOR DPD RI DALAM TINJAUAN TEORI KEPRIBADIAN KELOMPOK RAYMOND CATTELL. MEDIAKOM: Jurnal Ilmu Komunikasi, 03(01), 1-12. https://doi.org/http://dx.doi.org/10.32528/mdk.v3i1

Gunawan, I. (2016). Metode Penelitian Kualitattif. Pendidikan.

Hamna, D. (2017). EKSISTENSI JURNALISME DI ERA MEDIA SOSIAL. Jurnal Jurnalisa. https://doi.org/10.24252/jurnalisa.v3i1.3090

Herdiansyah, H. (2010). Metodologi penelitian kualitatif untuk ilmu-ilmu sosial. In Jakarta: Salemba Humanika.

Jandevi, U. (2019a). Communication strategy to improve women's political participation in Indonesia. International Journal of Communication and Society, 1(2), 68-81. https://doi.org/10.31763/ijcs.v1i2.46

Jandevi, U. (2019b). New media for increasing political participation in Indonesia. International Journal of Communication and Society, 1(1), 1-8. https://doi.org/10.31763/ijcs.v1i1.19

Jaya, K. (2019). Venezuela's communication dynamics in rejection of humanitarian assistance from United States of America. International Journal of Communication and Society, 1(1), 26-33. https://doi.org/10.31763/ijcs.v1i1.5

King, G. R. D. (1991). Cresswell Research Design. Muqarnas.

Meersohn, C. (2005). Introducción a Teun Van Dijk: Análisis de Discurso. Cinta de Moebio.

Moleong, L. (2006). Metodologi penelitian. Kualitalif Sasial.

Nursam, N. (2017). Manajemen Kinerja. Kelola: Journal of Islamic Education Management. https://doi.org/10.24256/kelola.v2i2.438

Pujileksono, S. (2009). Masalah-Masalah Di Penjara Dalam Studi Sosial. Jurnal Salam.

Rahardjo, M. (2017). Studi Kasus Dalam Penelitian Kualitatif. In Вестник Росздравнадзора.

Rahmat, P. S. (2009). Penelitian Kualitatif. Journal Equilibrium.

Schramm, G. (1994). A Practical Approach to Rheology and Rheometry. Rheology.

Sugiyono. (2016). Memahami Penelitian Kualitatif. Bandung: Alfabeta.

Ulfah, M., \& Barry, A. (2019). Indonesia Leader Forum, post-truth and political interests in social media and television. International Journal of Communication and Society, 1(1), 17-25. https://doi.org/10.31763/ijcs.v1i1.18

Winarno, B. (2012). Kebijakan Publik (Teori, Proses, dan Studi Kasus). Caps. 